\title{
Empréstimos do Português na língua Mehináku (Arawak)
}

DOI: http://dx.doi.org/10.21165/el.v49i1.2476

\section{Paulo Henrique de Felipe'}

\section{Resumo}

Com a colonização do país e, consequentemente, a mistura de povos etnicamente diferentes, muitas foram as mudanças, de caráter diverso e assimétrico, sofridas pelas línguas em contato. Ao longo da trajetória histórica e política do Brasil, por exemplo, muito se tem discutido a respeito dos processos linguísticos oriundos desse contato, bem como sua implicação para os sistemas das línguas em convívio. Tais estudos, em sua maioria, versam em analisar o sistema do Português e o modo como ele foi influenciado pelas línguas com as quais conviveu. Tomando um sentido contrário, neste trabalho buscaremos refletir a respeito de como se dão os empréstimos linguísticos do português na língua Mehináku (Arawak), a fim de traçar um panorama geral dos tipos mais comuns de empréstimos linguísticos presentes neste idioma.

Palavras-chave: empréstimos linguísticos; língua Mehináku; língua portuguesa.

1 Universidade Estadual de Campinas (UNICAMP), Campinas, São Paulo, Brasil; pauloh2sp@gmail.com; https://orcid.org/0000-0001-6607-5417. 


\title{
Portuguese loanwords in Mehináku Arawakan language
}

\begin{abstract}
The Brazil's colonization and the consequent mix of ethnically different people resulted in many diverse and asymmetrical changes for the languages in contact. Throughout Brazil's historical and political path, much has been discussed about the linguistic processes arising from this contact and their implications for the language systems in interaction. Most of these studies analyze the Portuguese system and the way it was influenced by the languages with which it interacted. Conversely, we will reflect on how the Portuguese loanwords are used in Mehináku Arawakan language, in order to give an overview of the most common types of loanwords present in this language.
\end{abstract}

Keywords: Loanwords; Mehináku language; Portuguese language.

\section{Considerações iniciais}

Muitas são as transformações que o contato entre línguas impõe aos sistemas linguísticos dos idiomas em relacionamento. As mudanças podem afetar os mais diversos níveis de organização da linguagem, como a fonologia, a morfologia, a sintaxe e/ou o léxico. Sapir (1969) afırma que as línguas do mundo podem, em princípio, sofrer influências do ambiente quanto ao seu "assunto ou conteúdo", ou seja, seu léxico. No léxico de uma língua, em função de sua maleabilidade histórica e social, estão alocadas todas as ideias, crenças e formas de conhecimento de um povo. É pelo léxico e, consequentemente, pela semântica das palavras que o subjaz, que somos capazes de entender a riqueza material da comunidade que o utiliza, bem como o nível de importância que esta comunidade dá às coisas e seres que nomeia. A este respeito, Sapir (1969, p. 43) menciona:

\begin{abstract}
O léxico da língua é que mais nitidamente reflete o ambiente físico e social dos falantes. O léxico completo de uma língua pode se considerar, na verdade, como o complexo inventário de todas as ideias, interesses e ocupações que açambarcam a atenção da comunidade; e, por isso, se houvesse à nossa disposição um tesouro assim cabal da língua de uma dada tribo, poderíamos daí inferir, em grande parte, o caráter do ambiente físico e as características culturais do povo considerado.
\end{abstract}

Para o autor, seria uma completa ilusão imaginarmos, a priori, que alguém se ajuste à realidade sem o auxílio essencial da língua e que a língua seja, meramente, um meio ocasional de resolver problemas específicos de comunicação ou raciocínio. O fato incontestável é que o "mundo real" se constrói inconscientemente, em grande parte das vezes, na busca dos hábitos linguísticos do grupo. Não há duas línguas que sejam bastante semelhantes para que se possa dizer que representam a mesma realidade social. Os mundos em que vivem as diversas sociedades humanas são distintos e não 
apenas um mundo com muitos rótulos diversos (SAPIR, 1929). É dessa vicissitude de relações entre povos e línguas que se encontram e se relacionam, portanto, que urgem os mais diversos e variados fenômenos linguísticos e, para não esquecer, culturais. Os empréstimos, nessa perspectiva, não poderiam ficar de fora, haja vista que traduzem, em virtude de seu caráter linguístico e social, a relação entre língua, cultura e pensamento dos povos em convívio. Para Sapir (1933, p. 36), "o vocabulário é um índice bastante sensível da cultura de um povo e as mudanças de sentido, a perda de velhas palavras, a criação e empréstimo de novas são todas dependentes da história da cultura".

Embora os elementos lexicais pareçam ser, de fato, um conjunto fértil ao empréstimo, não se pode dizer que as línguas do mundo emprestem apenas elementos dessa natureza. Haspelmath (2008) aponta a existência de uma escala de emprestabilidade (borrowability scale), na qual estariam dispostos os elementos emprestados em ordem de uma maior ou menor frequência de ocorrência. Proposta por Field (2002), esta escala compreenderia: itens de conteúdo > palavras funcionais > afixos aglutinantes > afixos fusionais. A vantagem da escala de emprestabilidade de Field (2002) está no fato de ela propor que afixos aglutinantes são mais facilmente emprestados do que afixos fusionais, haja vista que o restante da hierarquia de emprestabilidade das categorias já era de conhecimento de boa parte dos linguistas que lidam com questões de contato e empréstimo linguístico. Não seria novidade dizer, nessa perspectiva, que itens lexicais são mais provavelmente emprestados do que itens gramaticais e que palavras são mais facilmente emprestadas do que morfemas presos.

Assim, embora não sejam apenas os elementos lexicais os emprestados pelas línguas em situação de contato, como mostrou a escala de Field (2002), eles parecem ser os que mais facilmente sofrem esse tipo de processo. Do conjunto de itens de conteúdo, e das partes do discurso, por conseguinte, os substantivos são os mais amplamente reconhecidos por serem tomados por empréstimo e, mesmo verbos, quando emprestados, são utilizados, frequentemente, como se fossem nomes. Vê-se, assim, como afırmarmos no início do artigo, que existe uma relação mútua entre o léxico e os demais componentes gramaticais das línguas.

Pensando dessa forma, este trabalho buscará analisar, a partir dos dados coletados em nossos últimos trabalhos de campo, os itens lexicais do Português tomados por empréstimos pela língua Mehináku, a fim de verificar de que modo esses elementos foram incorporados ao sistema linguístico desse idioma. Usaremos como perspectiva teórica para a análise dos empréstimos a proposta teórica de Haugen (1950) e a reanálise que Winford (2003) fez de sua proposta.

O artigo está dividido da seguinte forma: na seção 1, faremos uma breve apresentação da língua e do povo Mehináku; na seção 2, apresentaremos nosso arcabouço teórico e, na seção 3, apresentaremos os exemplos de empréstimos em Mehináku, a partir da proposta teórica escolhida, seguido da conclusão e das referências. 


\section{A língua e o povo Mehináku}

Os índios Mehináku do Brasil central são, segundo Gregor (1982), um dos vários grupos de indígenas que vivem e compõem aldeias muito similares ao longo dos formadores do rio Xingu, um dos grandes tributários do Amazonas. De acordo com o Instituto Socioambiental (ISA, 2006), os Mehináku são habitantes da área cultural conhecida como Alto Xingu e fazem parte de um amplo complexo de povos que, embora compartilhem muitas semelhanças, em especial em relação à língua e à cultura, são diferentes entre si.

Os Mehináku falam uma língua de mesmo nome, pertencente à família Arawak. Ainda de acordo com o ISA (2006), estima-se que a língua Mehináku seja falada por aproximadamente 250 pessoas que habitam a região do rio Kurisevo, no Parque Indígena do Xingu, Mato Grosso, Brasil.

De Felipe (2019), no entanto, discorda desses números. Segundo o autor, em pesquisas de campo recentes percebeu-se que esse número está desatualizado, uma vez que somente na aldeia Utawana há cerca de 180 indígenas. Acreditamos, portanto, que a língua Mehináku seja falada, atualmente, por mais de 400 indígenas no total. A população distribui-se em quatro aldeias, são elas: (i) Uyaipiyuku, que é a mais antiga e da qual derivaram as demais aldeias, e que é dirigida pelo cacique Yumui Mehináku; (ii) Utawana, que desde o início de 2016 tem sido dirigida pelo cacique (e também pajé) Tukuyari; (iii) Kaupüna, que foi criada por Makaulaka Mehináku, filho de Yahati Mehináku (antigo cacique da aldeia Utawana), após ter retornado da Universidade de Brasília, onde fez seu mestrado em Linguística e (iv) Aturua, atualmente dirigida pelo cacique Amunai, irmão do cacique da aldeia Uyaipiyuku.

A aldeia Utawana é a mais próxima da área urbana, localizada a cerca de 35 quilômetros da cidade de Gaúcha do Norte (MT). Esta aldeia mantém certa proximidade com as aldeias Kaupüna e Aturua, de modo que é possível se locomover de uma a outra mais rapidamente, seja por meio de carro, na época da seca, ou por barco, na época da cheia do rio Kurisevo. A aldeia Uyaipiyuku, por sua vez, é a mais distante das quatro mencionadas acima, e está situada a aproximadamente 4 horas de viagem de barco da aldeia de Utawana. Nossas pesquisas de campo, cujos dados coletados servem de base para a análise apresentada neste artigo, foram feitas na aldeia Utawana, segunda maior entre as quatro aldeias habitadas por povos Mehináku.

\section{Arcabouço teórico adotado}

Antes de apresentar o arcabouço teórico usado no trabalho, é necessário deixar clara a terminologia linguística utilizada nesta pesquisa. Tal como consta na literatura, iremos assumir os termos língua receptora, para aquele idioma que, numa situação de contato, recebe influência, ou seja, empresta elementos de outra língua, incorporando-os a seu 
sistema linguístico e língua fonte, para aquela que influencia, doa ou fornece os elementos linguísticos para a outra língua.

Haugen (1950), ao tratar da questão dos empréstimos, os conceitua como a tentativa de reprodução, numa determinada língua, de padrões pertencentes à outra língua. Esta tentativa, que não é, segundo o autor, uma simples imitação, consiste na tentativa de reprodução natural da palavra original. Assim, ao ser transferido da língua fonte para a língua receptora, durante o processo de empréstimo, tal item lexical sofre um processo de reanálise, uma adequação ao padrão silábico ou uma adaptação fonológica e gramatical. Dessa forma, na tentativa de reproduzi-lo, o falante pode substituir um traço fonológico por um padrão similar em sua língua, em virtude da comparação que faz entre os dois sistemas linguísticos.

O tipo de substituição mais descrito na literatura é o de padrões fonéticos, no entanto, podemos observar também a existência de substituição de padrões morfológicos e sintáticos. Esses processos de adaptação, transferência, importação, tradução, dentre outros, de um determinado item emprestado, têm recebido, de acordo com Haugen (1950), classificações variadas, a depender do modo como são adaptados pela língua receptora. Segundo o autor, basta uma breve incursão à literatura pertinente para encontramos rótulos como loanwords, hybrid, loan translation ou semantic loan. Todas essas taxonomias, contudo, não são suficientes, segundo Haugen (1950), para explicar a complexidade do processo de empréstimo linguístico, em virtude de sua demasiada generalidade.

É em virtude dessa generalidade, aliás, que Haugen (1950) alerta para a confusão feita entre estes tipos de empréstimos. É comum encontrar, na literatura linguística, exemplos de loanword sendo tratados como hybrid, e empréstimos do tipo loan translation sendo tratados como semantic loan. Como exemplo do primeiro tipo, o autor apresenta a palavra "shivaree", que em inglês significa uma espécie de serenata e que foi adaptado da palavra francesa "charivari", em que os falantes adotaram não apenas o significado do termo, como também sua forma, com apenas algumas substituições de fonemas nativos. 0 equívoco em associar esse tipo de empréstimo ao tipo hybrid se dá em virtude de o último não abranger apenas aspectos fonológicos na adaptação do termo à língua receptora. Embora a definição dos empréstimos do tipo hybrid (aqueles em que apenas uma parte da forma fonética da palavra foi importada, enquanto a outra parte é composta de formas nativas) possa se confundir com o tipo loanword, é necessário diferenciá-los. O Alemão Pensilvânico ao adotar, por exemplo, a palavra plum pie "torta de ameixa" do Inglês, passou a utilizá-la como [blaøməpar], em que o morfema [par] foi importado, mas a forma nativa [blavmə] substituiu a forma estrangeira plum. Isso mostra, claramente, que os falantes do Alemão Pensilvânico analisaram o composto ainda quando o estavam emprestando, haja vista que somente assim poderiam ter realizado a substituição parcial. Esta distinção coloca o processo de empréstimo do tipo hybrid em um nível diferente da substituição 
meramente fonêmica do tipo anterior, de modo que somos obrigados, pela evidência dos fatos, a postular uma substituição morfêmica que opera independentemente da fonêmica.

Tais inconsistências terminológicas dizem respeito, também, aos empréstimos do tipo loan translation e semantic loan. Os do primeiro tipo, segundo Haugen (1950), consistem na adaptação de ambas as partes da palavra emprestada, por parte dos falantes da língua receptora, enquanto os do segundo tipo consistem na importação apenas do significado da palavra estrangeira, com a total adaptação de sua forma à estrutura da língua receptora. Em razão dessas definições muito gerais, é comum encontrarmos equívocos na delimitação de um ou outro tipo de empréstimo. Ao apresentarmos, a título de ilustração, um exemplo do tipo loan translation, como a palavra skyscraper "arranha céu", do Inglês, que, tendo sido emprestada por falantes do Espanhol, assumiu a forma rascacielos, veremos que ela se aproxima muito dos exemplos apresentados para o tipo semantic loan, como é o caso da palavra "humoroso"2, do Português Americano, adotada do Inglês "humorous". A inconsistência de uma afirmação como esta subjaz no fato de que, provavelmente, os empréstimos do tipo loan translation são facilmente confundíveis com os do tipo semantic loan, já que em ambas as construções os falantes não utilizam um padrão estrutural particular, mas importam o significado do termo da língua fonte.

No intuito de solucionar tais questões, Haugen (1953) elaborou uma sistematização específica para os empréstimos linguísticos, a depender do tipo de comportamento estrutural que adquirem nas línguas receptoras. Como já dito anteriormente, sua proposta foi mais tarde ampliada por Winford (2003), que acrescentou a noção de "criações formadas somente a partir de morfemas estrangeiros" ao rol das possibilidades de empréstimo linguístico.

É importante pontuar também que o que os autores tratam como criações nativas, e incluem dentro do quadro dos empréstimos linguísticos, pode também ser entendido, como se vê tradicionalmente na literatura linguística, como neologismos. Embora essa discussão seja muito ampla e envolva muitas definições, nos ateremos aqui à possibilidade de o que estamos representando na seção de criações nativas sejam neologismos em Mehináku, em virtude do significado que expressam. Em outras palavras, iremos considerar como empréstimos as palavras modeladas pela língua fonte e como neologismos as criações vernáculas do Mehináku que expressam referentes alóctones.

2 Haugen (1950), ao utilizar o termo "humoroso" na exemplificação do tipo semantic loan de empréstimo, utilizou-se do trabalho de Leo Pap, conforme citação do autor: "The examples from AmPort. are taken from Leo Pap, Portuguese-American speech (New York, 1949)". Esta palavra, embora não pareça familiar no Português falado, em virtude da obsolescência de seu uso, pode ser encontrada na modalidade escrita da língua, em que adquire o sentido de "humorado" ou "aquele que tem humor", e cuja etimologia remonta ao latim tardio (FERREIRA, A. B. de H. Novo Aurélio Século XXI: o dicionário da Língua Portuguesa. 3. ed. Rio de Janeiro: Nova Fronteira, 1999). 
Vejamos abaixo um esquema adaptado da proposta de ambos os autores, em que, por inserção nossa, estamos chamando as criações nativas de neologismos:

\section{Empréstimos (modelados pela língua fonte):}

\section{Tipo A: Loanwords}

1. Loanword Puro:

Importação morfêmica total de uma palavra simples ou composta, variando os graus de substituição fonêmica.

2. Loanblend: Combinação de morfemas nativos e importados.

2a. Blend derivacional:

Raiz importada + Afixos nativos ou Raiz nativa + Afixos importados

2b. Blend composto:

Raiz importada + Raiz nativa.

\section{Tipo B: Loanshifts (empréstimos com significado)}

Mudança na semântica da palavra nativa sob influência da

1. Extensão palavra estrangeira

(empréstimos semânticos):

a. Semelhança fonológica: humoroso > humours.

b. Semelhança semântica parcial: frio (resfriado) > cold infection

2. Loan translation:

Combinação de morfemas nativos em imitação de padrões estrangeiros. Ex: skyscraper > arranha-céu > rascacielos.

\section{Criações Nativas (neologismos)}

1. Puramente Nativas:

2. Híbridas:

3. Usando apenas morfemas estrangeiros:
Uso inovador de palavras nativas para expressar conceitos estrangeiros.

Mistura de morfemas nativos e estrangeiros para expressar conceitos estrangeiros.

Combinação de morfemas estrangeiros para novos conceitos

É a união destas duas propostas que levaremos em consideração para o tratamento dos dados da língua Mehináku na seção seguinte. 


\section{Empréstimos e criações nativas em Mehináku}

Os empréstimos da língua Mehináku, a partir da proposta de Haugen (1953) e Winford (2003), estão concentrados basicamente em dois grandes eixos: dentro dos empréstimos modelados pela língua fonte, estão os (i) loanwords, que incluem os loanwords puros e os loanblends (do tipo blend derivacional) e, dentro da categoria das criações nativas, as (ii) puramente nativas (que inclui o uso de palavras nativas para expressar conceitos estrangeiros (neologismos)). Não encontramos na língua, portanto, exemplos de loanshifs ou de criações nativas hibridas ou que estejam usando apenas morfemas estrangeiros.

Estes empréstimos da língua Mehináku serão discutidos abaixo seguindo a mesma lógica de apresentação da proposta de Haugen (1950) e Winford (2003), ou seja, aquela em que se apresentam primeiramente os exemplos de empréstimos do tipo I (modelados pela língua fonte), inclusive seguindo a mesma numeração dada pelos autores para cada subseção da proposta, seguidos pelos exemplos de empréstimos do tipo II (criações nativas) ${ }^{3}$. Vejamos:

\section{Empréstimos (modelados pela língua fonte):}

\section{Tipo A: Loanwords}

1. Loanwords puros: importação morfêmica total de uma palavra simples ou composta, variando os graus de substituição fonêmica.

Os empréstimos desse tipo em Mehináku sofrem apenas adaptação fonológica. Ou seja, como o inventário fonológico da língua não dispõe de alguns fonemas encontrados nas palavras emprestadas, os falantes fizeram a substituição desses fonemas por outros que existem em sua língua. Para que fique mais clara essa substituição, apresentamos abaixo o inventário fonológico da língua Mehináku:

3 As seguintes abreviaturas são usadas nos exemplos: 1 'primeira pessoa'; 2 'segunda pessoa'; 3 'terceira pessoa'; CL 'classificador'; DIM 'diminutivo'; IPFV 'imperfectivo'; LOC 'locativo'; N- 'não' (exemplo: NPOSS 'não-possuído; NPROT 'não-prototípico'); POSS 'posse/possuído'; PROT 'prototípico'; SG 'singular'. 
Tabela 1. Inventário fonológico consonantal da língua Mehináku

\begin{tabular}{c|c|c|c|c|c|c|c|c|c|c}
\hline \multirow{2}{*}{ Obstruintes } & {$[$-cont $]$} & \multirow{2}{*}[\text{-voz}]{} & $\mathrm{p}$ & $\mathrm{t}$ & $\mathrm{ts}$ & $\mathrm{t}$ & & & $\mathrm{k}$ & \\
\hline & {$[$ +cont $]$} & & & & & & $\mathrm{s}$ & & & $\mathrm{h}$ \\
\hline \multirow{3}{*}{ Soantes } & {$[$ +cont $]$} & {$[$-nasal] } & $\mathrm{w}$ & $\mathrm{I}$ & $\mathrm{r}$ & & & $\mathrm{j}$ & & \\
\hline & {$[$-cont $]$} & {$[$ +nasal] } & $\mathrm{m}$ & $\mathrm{n}$ & & & & & & \\
\hline
\end{tabular}

Fonte: Elaboração própria

Reparemos que o inventário fonológico do Mehináku, composto por 13 consoantes, não apresenta consoantes vozeadas entre o conjunto das obstruintes. Por esta razão, quando estas consoantes figuram em palavras emprestadas do português, sofrem acomodação fonológica para o par homorgânico desvozeado correspondente. Essa substituição, embora não de forma homorgânica, também ocorre, por exemplo, com algumas soantes fonologicamente não existentes na língua, conforme veremos a seguir. Assim, do ponto de vista dessa substituição/acomodação fonológica, dois tipos de processos foram encontrados.

O primeiro é relativo às obstruintes. Neste caso, ocorre a substituição das consoantes vozeadas [b] e [d] existentes nas palavras emprestadas do português, mas não existentes fonologicamente em Mehináku, pelas suas contrapartes homorgânicas desvozeadas [p] e [t], que fazem parte do inventário fonológico da língua, como abaixo:

\begin{tabular}{|c|c|c|c|}
\hline & & Português & Mehináku \\
\hline a. & Balde & ['bawdzI] & ['pawd3I] \\
\hline b. & Fralda & ['frawde] & [fa'rawta] \\
\hline c. & Sabonete & [sabõ'net]I] & [sapu'netfI] \\
\hline d. & Batom & [ba'tõw] & [pa'tũ] \\
\hline e. & Computador & [kõmputa'doı] & [kuputa'tu] \\
\hline f. & Borracha & [bo'hafe] & [pu'haja] \\
\hline g. & Deus & ['dews] & ['tewsI] \\
\hline & Rádio & ['hadziw] & ['hatsiw] \\
\hline & Coberta & [ku'besta] & [ku'peta] \\
\hline
\end{tabular}

Notemos acima que a palavra ['bawdr] 'balde' é pronunciada como ['pawd3] 'paldi', ou ainda que a palavra ['dews] é pronunciada como ['tewsI], havendo a substituição das consoantes vozeadas [b e d] pelas desvozeadas [p e t]. O mesmo ocorre nos demais exemplos. 
O segundo tipo de substituição não mais opera com obstruintes, mas com soantes, e é aquele em que houve substituição das palatais [ $\Lambda$ ] e [n], que não existem fonologicamente na língua, pela palatal [j], conforme abaixo:

\begin{tabular}{|c|c|c|}
\hline & Português & Mehináku \\
\hline a. Colher & $\left.\left[\mathrm{ku}^{\prime} \wedge \varepsilon\right\rfloor\right]$ & {$\left[k u^{\prime} \mathbf{j} \varepsilon\right]$} \\
\hline b. Toalha & [tu'a人e] & [tu'aja] \\
\hline c. Calcinha & [kaw'sĩne] & [kaw'sija] \\
\hline
\end{tabular}

Há, ainda, outro processo em Mehináku, que estamos tratando como acomodação fonológica, mas que não tem a ver com a substituição de segmentos. Este processo é aquele em que houve adaptação dos empréstimos ao padrão silábico da língua. Como em Mehináku não existem encontros consonantais e consoantes em coda são proibidas, palavras emprestadas com essas características foram ressilabificadas. Vejamos:

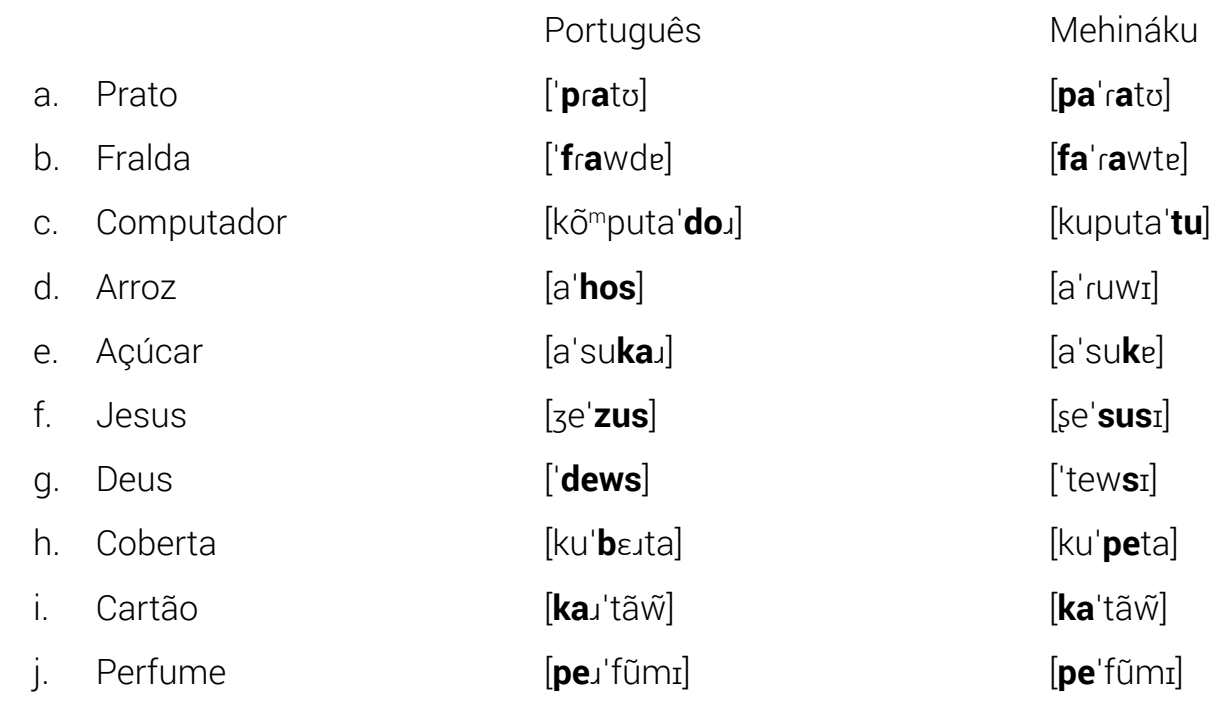

Notemos que, para evitar o encontro consonantal, que conforme já dito não ocorre na língua, os falantes ressilabificaram as palavras emprestadas. Assim, uma palavra como ['pratə] 'prato', do português, passou a ser pronunciada em Mehináku como [pa'ratø] 'paratu', evidenciado a criação de uma nova sílaba, que desfaz o encontro consonantal entre $<$ pr $>$, comum no português. Novas sílabas são criadas em Mehináku também para evitar a coda silábica. Não há consoantes fonológicas realizadas em coda silábica na língua, o que faz com que essas codas ou sejam apagadas, como na palavra [kõmputa'doı] 'computador', que se realiza como [kuputa'tu], em que o rótico que ocupa a coda da última sílaba da palavra é apagado, ou então ocorre a adição de uma nova sílaba que também desfaz a presença da consoante em coda, como na palavra [зe'zus] 'Jesus', que é pronunciada pelos falantes Mehináku como [š'susi], em que se acrescenta uma vogal [I] à sílaba final, deslocando a sibilante [s] em coda para a posição de ataque da próxima sílaba (a nova criada). 
Os exemplos acima evidenciam, portanto, casos de palavras simples em que houve importação morfêmica total, variando apenas os graus de substituição fonêmica, a depender das necessidades de acomodação fonológica da língua. Vamos agora ao segundo tipo de empréstimo em Mehináku, os loanblends, apresentados na seção seguinte.

\section{Loanblends: combinação de morfemas nativos e importados}

Em Mehináku, também há exemplos de loanblends. Dentre os tipos propostos por Haugen (1953) e Winford (2003), encontramos somente os loanblends derivacionais, constituídos por raiz importada + afixos nativos, conforme abaixo:

\section{2a. Blend Derivacional: raiz importada + afixos nativos}

Os exemplos que constituem os empréstimos deste tipo em Mehináku são os mesmos apresentados na seção acima, sobre os Loanwords puros. O que ocorreé que, após sofrerem acomodação fonológica, e serem, portanto, incorporados à língua, esses empréstimos passam a poder atuar, como qualquer outro nome do léxico, em construções variadas. É o caso, por exemplo, das construções de posse nominal em Mehináku. Quando possuídos, esses empréstimos passam a receber os morfemas indicativos de posse alienável.

É importante mencionar, aliás, que quase todos os empréstimos apresentados acima foram elicitados em sua forma possuída durante o trabalho de campo, ou seja, embora tenham sido apresentadas em suas formas despossuídas na seção anterior, para que se pudesse notar a acomodação fonológica decorrente do processo de empréstimo, a forma possuída desses itens parece ser a mais comum na língua. Com exceção das palavras para 'Deus' e 'Jesus', que são palavras não-possuíveis, todas as demais nos foram dadas em sua forma possuída. A seguir, retomamos somente alguns desses exemplos, a fim de que possamos ver em suas formas possuídas:

$\begin{array}{lllll} & \text { Forma despossuída } & \text { Forma possuída } & & \\ \text { Colher } & {[\mathrm{ku} \text { 'je }]} & \text { nu-ku'je-la } & \text { 1sG-colher-Poss } & \text { 'minha colher' } \\ \text { Prato } & \text { [pa'ratø] } & \text { nu-para'tu-la } & \text { 1sG-prato-Poss } & \text { 'meu prato' } \\ \text { Copo } & {[\text { 'kopv] }} & \text { nu-ko'pu-la } & \text { 1sG-copo-Poss } & \text { 'meu copo' } \\ \text { Balde } & {[\text { 'pawdzi }]} & \text { nu-paw'dzi-la } & \text { 1sG-balde-Poss } & \text { 'meu balde' } \\ \text { Toalha } & \text { [tu'aja }] & \text { nu-tua'ja-la } & \text { 1sG-toalha-Poss } & \text { 'minha toalha' }\end{array}$

Notemos que o processo de posse nominal dos nomes emprestados é o mesmo daqueles pertencentes à própria língua, ou seja, os nomes da língua nativa dos falantes. Todos os nomes recebem os afixos correspondentes à formação da posse alienável na língua, que 
são os prefixos pronominais, como no caso de nu- '1SG', e o sufixo marcador de posse alienável -la.

Há também, em Mehináku, o uso das palavras, dentre as quais algumas apresentadas anteriormente, em outros processos morfológicos que não a posse nominal. Nestes casos, também temos exemplos de empréstimos do tipo blend derivacional, uma vez que há a união de uma raiz importada a afixos nativos. Vejamos:

$\begin{array}{lll}\text { [ku'je kuhu'pitsi] } & \text { colher pontuda } & \text { 'garfo' } \\ \text { [pohafa-'kana] } & \text { borracha-CL.côncavo } & \text { 'vasilha de plástico' } \\ \text { [alata-'kana] } & \text { panela de lata-CL.côncavo } & \text { 'panela feita de alumínio' } \\ \text { [nu-trjijeru-la-'nai] } & \text { 1SG-dinheiro-Poss-Loc } & \text { 'carteira' } \\ \text { [tjijeru-pina-'naku] } & \text { dinheiro-casa-CL.dentro } & \text { 'banco (agência)' }\end{array}$

Reparemos que as palavras acima são empréstimos do português que sofreram acomodação fonológica e morfossintática na língua Mehináku. A palavra para "garfo", por exemplo, é construída com uma palavra importada (kuje) mais um adjetivo nativo (kuhu'pitsi); as palavras para "vasilha de plástico" e "panela de alumínio" são compostas por uma palavra importada (pohaja/alata) mais um classificador indicativo de característica côncava (-kana), como são naturalmente esses objetos; a palavra para "carteira", como está em sua forma possuída, é composta de um prefixo pronominal (nu-) mais a palavra importada (tfijeru) mais sufixos de posse (-la) e locativo (-naı); a palavra para "agência bancária", finalmente, é composta por uma palavra importada (tfijeru), por uma palavra nativa (p+na) e por um advérbio de lugar (-naku), que literalmente expressa a noção de "casa onde o dinheiro está dentro".

Todos esses exemplos, portanto, evidenciam a estreita relação entre léxico e gramática em Mehináku, sobretudo porque podemos ver como palavras emprestadas são acomodadas à fonologia e depois à morfossintaxe da língua e como o uso dessas palavras está fortemente ligado a estruturas gramaticais sem as quais seu funcionamento como empréstimo ficaria comprometido.

\section{Criações Nativas}

1. Puramente nativas: uso inovador de palavras nativas para expressar conceitos estrangeiros:

Estamos tratando as palavras dessa categoria como neologismos em Mehináku. Esses neologismos compõem boa parte das palavras coletadas e, em geral, são formados de palavras nativas acompanhadas também de morfemas nativos, a fim de designar ou 
representar referentes estrangeiros ou da língua alvo, no caso, o português. Como os exemplos são variados, vamos dividir a apresentação em dois tipos: (i) neologismos compostos por nomes + morfemas e (ii) neologismos compostos por um único nome ou pelo composto nome + nome.

Os neologismos do primeiro tipo são aqueles que têm como base um nome nativo, que é adjungido de afixos também nativos. Esses afixos, em geral, são morfemas classificadores, morfemas locativos e outros, conforme é possível ver abaixo:

\begin{tabular}{|c|c|c|}
\hline [uni-'kana] & água-CL.côncavo & 'vidro' \\
\hline [mahitfuki-'tf $\left.{ }^{4} a n a\right]$ & observador-CL.côncavo & 'televisão' \\
\hline [katika-kana-pai-naku-'itsa] & frio-CL.côncavo-IPFV-CL.dentro-LoC & 'geladeira' \\
\hline [eșu-ni'a-pi] & pesca-fio/ramo-CL.linear & 'linha (pesca)' \\
\hline [kana-tapa-'tì] & CL.côncavo-CL.volumoso-CL.semente & 'pulseira' \\
\hline [nisa-ja-'naku] & sangue-CL.líquido-CL.dentro & 'absorvente' \\
\hline [tulũ-'ti] & orelha-CL.semente & 'brinco' \\
\hline [jakai-'tjana] & fala-CL.côncavo & 'celular' \\
\hline [uku-na'ku-ta] & flecha-CL.dentro-CAUS & 'projétil' \\
\hline [ata-'pana] & árvore-CL.foliforme & 'folha' \\
\hline [uni-'tai] & água-DIM & 'espelho' \\
\hline [jana-'ti] & pintura-CL.semente & 'lápis/pincel' \\
\hline [jana-ta-'taku] & pintura-?-CL.plano/locativo & 'lousa' \\
\hline [jana-ti-'tJana] & pintura-CL.semente-CL.côncavo & 'escola' \\
\hline [ajama-kũ'mã'] & veado grande-NPROT & 'boi' \\
\hline
\end{tabular}

4 Ocorre palatalização de [k] quando vem depois de [i]. Nesses casos, a forma fonológica do morfema é /kana/, que se realiza como /tfana/ em contexto [i]

5 Estamos tratando o morfema /-kuma/ como não-prototípico, no sentido de Coleman e Kay (1981). Para os autores, prototípico é o melhor exemplo de uma categoria. Os autores citam o caso da palavra 'sparrow' (pardal), que em Inglês pode ser tomado como exemplo prototípico do grupo dos pássaros, enquanto galinha, peru e pinguim, que também são pássaros (em Inglês, uma vez que em português temos dois grupos distintos para tratar desses animais dentro da classe maior das aves, são eles: pássaros e aves), não podem ser considerados exemplos prototípicos de pássaros. Nesse sentido, estamos assumindo que este morfema tem a função de indicar nãoprototipicidade em Mehináku, sobretudo porque, se tomarmos como exemplos as palavras da língua nas quais ele figura, em sua totalidade palavras relacionadas a animais da cultura não indígena, veremos que sua função é indicar que determinado animal, embora se pareça/seja semelhante a um animal eleito como prototípico da cultura Mehináku, não é este animal. Assim, ao 


$\begin{array}{lll}\text { [arau-kư'mã] } & \text { espécie de ave-NPROT } & \text { 'galinha' } \\ \text { [awajulu-kũ'mã] } & \text { raposa-NPROT } & \text { 'cachorro' } \\ \text { [autu-kũ'mã] } & \text { catitu-NPROT } & \text { 'porco' } \\ \text { [mukuti-kũ'mã] } & \text { rato-NPROT } & \text { 'coelho' } \\ \text { [ketu'la-ja] } & \text { seiva de pequi-CL.líquido } & \text { 'bola' } \\ \text { [kitsapa-nã-ni'a-pi] } & \text { pé-roupa-fio/ramo-CL.linear } & \text { 'cadarço' } \\ \text { [ipiw-'taku] } & \text { tartaruga-CL.plano/locativo } & \text { 'dois reais' } \\ \text { [wakala-'taku] } & \text { garça-CL.plano/locativo } & \text { 'cinco reais' } \\ \text { [arara-'taku] } & \text { arara-CL.plano/locativo } & \text { 'dez reais' } \\ \text { [kapulu-kũmã-'taku] } & \text { bugio-NPROT-CL.plano/locativo } & \text { 'vinte reais' } \\ \text { [janumaka-'taku] } & \text { onça-CL.plano/locativo } & \text { 'cinquenta reais' } \\ \text { [jaitsapa-'taku] } & \text { tucunaré-CL.plano/locativo } & \text { 'cem reais' }\end{array}$

Os neologismos do segundo tipo são aqueles formados por um único nome que expressa uma ideia estrangeira ou pelo composto de dois nomes nativos como base. Esses nomes podem ser possuídos, e, portanto, podem portar morfemas indicativos de pessoa, no caso, os prefixos pronominais reduzidos da língua, mas também podem figurar em sua forma despossuída. Os nomes alienáveis não portam morfemas quando não possuídos, mas os nomes inalienáveis, como partes do corpo, devem obrigatoriamente portar morfema indicativo de 'não-possuído (NPOSS)', quando aparecem sem um possuidor especificado, como no caso de [ututa-i] 'olho', que forma o empréstimo [ututa-i-'naî] 'óculos' (literalmente: roupa do olho) e outros que podem ser vistos abaixo:

$\begin{array}{lll}\text { [i'himia] } & \text { vento } & \text { 'ventilador' } \\ \text { [na'î] } & \text { roupa } & \text { 'camiseta' } \\ \text { ['itsa] } & \text { canoa } & \text { 'carro/avião/barco/moto' } \\ \text { [jawala'wi] } & \text { espinho de macaúba } & \text { 'agulha' } \\ \text { ['itsa i-'kiri] } & \text { canoa 3sG-nariz } & \text { 'frente do veículo' } \\ \text { [kaşa'ipa i-'taku] } & \text { não indígena 3sG-CL.locativo } & \text { 'cidade' } \\ \text { [a'pui] } & \text { caminho/trilha } & \text { 'estrada' } \\ \text { [ututa-i-'nail] } & \text { olho-NPoss-roupa } & \text { 'óculos' } \\ \text { [put-i-'nãi] } & \text { coxa-NPoss-roupa } & \text { 'calça' }\end{array}$

criarem palavras como [awajulu-kũ'mã] 'cachorro-NPROT', que deriva da palavra [awa'julu] 'raposa', os indígenas estão assinalando que o animal cachorro se parece com o animal raposa, mas que não é um indivíduo prototípico desse grupo. 


\begin{tabular}{|c|c|c|}
\hline [kitsa'pa-i-'nail] & pé-NPOSS-roupa & 'sapato/tênis' \\
\hline [kapiti'w-i-'nãi] & dedo-NPoss-roupa & 'anel' \\
\hline ['uni ka'tika] & água frio & 'gelo' \\
\hline
\end{tabular}

Há ainda na língua um único neologismo que não se encaixou em nenhuma das categorias acima, que é a palavra [i'jaw] 'gato' que se trata de uma onomatopeia que remete ao miado emitido por esse animal.

\section{Considerações finais}

Vimos, pelos dados apresentados, que a língua Mehináku dispõe tanto de estratégias modeladas pela língua fonte, quanto de estratégias de criação vernácula na/para a utilização de elementos importados. No primeiro caso, aquele que se refere aos empréstimos modelados pela língua fonte, os tipos mais comuns de empréstimos são os loanwords puros e os loanblends (derivacionais). No segundo caso, por outro lado, aquele que se refere às estratégias nativas de criação de palavras para designar conceitos estrangeiros, o tipo mais comum de empréstimo é o de criação puramente nativa. Loanshifts, que compõem o tipo $\mathrm{B}$ de empréstimos modelados pela língua fonte, e criações híbridas e usando apenas morfemas estrangeiros, que compõem a categoria das criações nativas, não foram encontrados em Mehináku

Além disso, pelos exemplos apresentados é possível ter uma visão geral a respeito dos neologismos em Mehináku e de como o léxico está intimamente ligado à estrutura gramatical dessa língua, como evidenciam os afixos marcadores de pessoa, os morfemas classificadores, e os locativos, dentre outros, que são anexados às palavras emprestadas ou criadas pelos falantes, para designar referentes estrangeiros.

\section{REFERÊNCIAS}

COUTO, H. do. Ecolinguística: estudo das relações entre língua e meio ambiente. São Paulo: Thesaurus Editora, 2007.

COLEMAN, L.; KAY, P. Prototype semantics: The English word lie. Language 57, p. 26-44, 1981.

DE FELIPE, P. H. P. S. Numerais na língua Mehináku (Arawak). Estudos Linguísticos (São Paulo. 1978), v. 48, n. 2, p. 786-799, 2019.

FIELD, F. W. Linguistic borrowing in bilingual contexts. Amsterdam: Benjamins, 2002. 
GREGOR, T. Mehináku: o drama da vida diária em uma aldeia do Alto Xingu. São Paulo: Companhia Editora Nacional, 1982.

HASPELMATH, M. Loanword typology: Steps toward a systematic cross-linguistic study of lexical borrowability. In: STOLZ, T.; BAKTER, D.; PALOMO, R. S. (org.): Aspects of Language Contact. New Theoretical, Methodological and Empirical Findings with Special Focus on Romancisation Processes. Berlin, New York: Mouton de Gruyter, 2008. p. 43-62.

HAUGEN, E. The Norwegian language in America. 2 vols. Philadelphia: University of Pennsylvania Press, 1953.

HAUGEN, E. The analysis of linguistic borrowing Language, v. 26, n. 2, p. 210-231, 1950.

INSTITUTO SOCIOAMBIENTAL (ISA). Povos indígenas no Brasil: 2001-2005. São Paulo: Instituto Socioambiental, 2006.

MATRAS, Y. Language contact. Cambridge: Cambridge University Press, 2009.

RODRIGUES, A. D. Línguas brasileiras - para o conhecimento das línguas indígenas. São Paulo: Loyola, 1986.

SAPIR, E. Língua e ambiente. Lingüística como ciência. Ensaios. Livraria Acadêmica, 1969. p. 43-62.

SAPIR, E. The Status of Linguistics as a Science. Language, v. 5, n. 4, p. 207-214, 1929 a.

SAPIR, E. Language. In: MANDELBAUM, D. G. Edward Sapir: culture, language and personality. Selected essays. University of California Press, 1933. p. 1-49.

STAUB, A. O empréstimo linguístico: um estudo de caso. Brasília: Livraria Editora Acadêmica, 1983.

THOMASON, S.; KAUFMAN, T. Language contact, creolization, and genetic linguistics. Berkley: University of California Press, 1991. 
WEINREICH, U. Languages in contact: findings and problems. The Hague: Mouton, 1974.

WINFORD, D. An introduction to contact linguistics. Blackwell Publishing, 2003.

WINFORD, D. Contact-induce change. Classification and Process. Diachronia, v. 22, p. 375427, 2005. 